\title{
Um Olhar Habermasiano sobre o Silenciamento da Formação para Avaliar nas Diretrizes Curriculares Nacionais das Licenciaturas em Matemática
}

\author{
A Habermasian View at the Silencing of Training to Evaluate in the \\ National Curriculum Guidelines for Mathematics Teacher Education
}

\author{
Thais Paschoal Postingue* \\ ORCID iD 0000-0002-9849-6870 \\ Deise Aparecida Peralta** \\ ORCID iD 0000-0002-5146-058X
}

\begin{abstract}
Resumo
Este artigo relata uma pesquisa que busca analisar, segundo a Teoria da Ação Comunicativa, as Diretrizes Curriculares Nacionais para a Formação Inicial e Continuada em Nível Superior de Profissionais do Magistério para a Educação Básica e as Diretrizes Curriculares para os cursos de Licenciatura e Bacharelado em Matemática. Definindo-se metodologicamente como análise documental, a investigação pauta-se na busca por evidências, orientações, prescrições e/ou menções relacionadas com o compromisso de formar professores para avaliar aprendizagens no ensino de Matemática. Os resultados evidenciam características de valorização do conhecimento específico em Matemática, próprias de modelos de formação amparados em racionalidade técnica, e de omissão em relação aos conhecimentos vinculados à prática de avaliação da aprendizagem como uma necessidade formativa para futuros professores de Matemática.
\end{abstract}

Palavras-chave: Formar para Avaliar. Avaliação. Currículo. Habermas.

\begin{abstract}
This article reports a research that seeks to analyze, according to the Theory of Communicative Action, the National Curriculum Guidelines for the Initial and Continuing Education of Higher Education Teachers for Basic Education and the Curriculum Guidelines for the Degree and Bachelor of Mathematics courses. Methodologically defined as documentary analysis, the research is based on the search for evidence, guidance, prescriptions, and/or mentions related to the commitment to train teachers to evaluate learning in mathematics teaching. The results show characteristics of valuing specific knowledge in mathematics, characteristic of training models based on technical rationality, and omission in relation to knowledge linked to the practice of learning assessment as a formative need for future mathematics teachers.
\end{abstract}

Keywords: Form to Evaluate. Evaluation. Curriculum. Habermas.

\footnotetext{
* Doutoranda pelo Programa de Pós-Graduação em Educação para a Ciência, da Faculdade de Ciências da Universidade Estadual Paulista (UNESP). Professora na Secretaria de Educação do Estado de São Paulo, São Paulo, Brasil. Endereço para correspondência: ST-PPG Av. Eng. Luiz Edmundo Carrijo Coube, 14-01, Vargem Limpa, Bauru, São Paulo, Brasil, CEP 17033-360. E-mail: thais.p.postingue@ unesp.br.

${ }^{* *}$ Doutora em Educação para a Ciência pela Faculdade de Ciências da Universidade Estadual Paulista (UNESP). Professora da Faculdade de Engenharia de Ilha Solteira (FEIS) da Universidade Estadual Paulista (UNESP), Ilha Solteira, São Paulo, Brasil. Endereço para correspondência: Av. Brasil Sul, 56, Centro, Ilha Solteira, São Paulo, Brasil, CEP: 15385-000. E-mail: deise.peralta@unesp.br.
} 


\section{Introdução}

Em investigação anteriormente realizada (POSTINGUE; PERALTA, 2018) foram analisados os projetos políticos pedagógicos dos cursos de licenciatura em Matemática de três universidades estaduais paulistas - UNESP, USP e UNICAMP - identificando aspectos da formação para avaliar à luz da Teoria da Ação Comunicativa (TAC), conforme defende Habermas (2012a, 2012b). Nos resultados da referida investigação, constatou-se preocupação, predominantemente, técnica, metódica, calculada, ou seja, as menções do formar para avaliar aprendizagens estão próximas a características instrumentais, antagônicas ao que Jürgen Habermas defende como desejável nas interações mediadas no mundo social.

Os pressupostos evidenciados privilegiam aspectos de formação específica de/em Matemática, além de ações isoladas de discussão do avaliar somente em disciplinas "clássicas" de formação pedagógica como Didática e Prática de Ensino, sugerindo que nos currículos dos cursos investigados há espaços e lugares díspares e dissociados para as dimensões da formação de professoras e professores de Matemática. Especificamente, a formação para avaliar descrita nos cursos analisados não supera um modelo de racionalidade atrelado aos aspectos técnicos, distanciando da racionalidade comunicativa, comprometida com a construção coletiva,

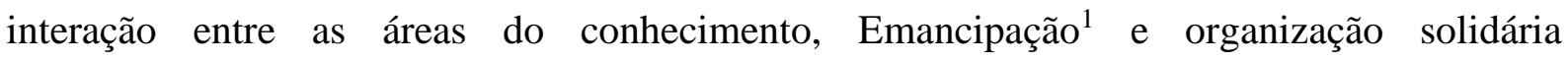
(POSTINGUE; PERALTA, 2018).

Motivadas pelos resultados dessa investigação anteriormente realizada e considerando a necessidade de o professor atuar em contextos que exigem o avaliar como prática diária, uma formação de professores de Matemática deveria concentrar ênfase em ações estruturadas que caracterizassem um formar para avaliar. E, em termos de tentativa de mínimas garantias, com ciência de que se trata de condição necessária, mas não suficiente, formar para avaliar aprendizagem de conteúdos curriculares de Matemática talvez devesse estar previsto nas ações apregoadas por diretrizes nacionais que regem a formação de professores de Matemática.

Em consonância com o acima exposto, a investigação que agora passamos a descrever neste artigo assenta-se em analisar, especificamente, a racionalidade presente no discurso das Diretrizes Curriculares Nacionais para a Formação Inicial e Continuada em Nível Superior de Profissionais do Magistério para a Educação Básica, as Diretrizes Curriculares para os cursos de Licenciatura e Bacharelado em Matemática, de acordo com os pressupostos da TAC de

\footnotetext{
${ }^{1}$ Os termos com carga conceitual de Habermas serão abordados com letra inicial maiúscula, como Entendimento, Consenso, Emancipação, Ação Estratégica, Ação Comunicativa e Atos de Fala, a menos que se tratarem de citação literal.
} 
Habermas (2012a, 2012b), especificamente no que se refere à avaliação na formação inicial de professores de Matemática.

Para tanto, metodologicamente, a pesquisa assenta-se na análise documental qualitativa (CELLARD, 2008), adotando uma perspectiva descritiva e interpretativa da racionalidade subjacente ao discurso oficial sobre diretrizes para a formação de professores de Matemática (BRASIL, 2002, 2003; 2015a; 2015b). No seu desenvolvimento, foram levantadas as Diretrizes Curriculares Nacionais para a Formação Inicial e Continuada em Nível Superior de Profissionais do Magistério para a Educação Básica (BRASIL, 2015b) e as Diretrizes Curriculares para os cursos de Licenciatura e Bacharelado em Matemática (BRASIL, 2003) com o intuito de buscar descrições/recomendações/menções e orientações que se relacionem a formar para avaliar no ensino de Matemática. Não se trata, contudo de uma análise exaustiva dos documentos, mas de provocar desassossego em relação a concepções e perspectivas curriculares para a formação de professores e a necessidade do formar para avaliar no ensino de Matemática, tendo a teoria social habermasiana como pano de fundo e o seu Agir Comunicativo como um horizonte a vislumbrar.

O procedimento de análise dos documentos segue os seguintes passos: 1) Olhar crítico sobre os documentos a partir da percepção habermasiana (procura por trechos nos documentos que expressem preocupação com espaços nos cursos que discutissem avaliação e formar para avaliar, além das abordagens clássicas e pontuais); 2) Identificar e discutir as evidências, menções e/ou descrições sobre a formação para avaliar aprendizagens (palavras e/ou expressões que pudessem ser vinculadas a diretrizes para formar para avaliar); 3) Evidenciar a racionalidade por meio da caracterização dos Atos de Fala empregados nos documentos analisados. O olhar das pesquisadoras esteve orientado a uma possibilidade de encontrar características, de desenvolvimento e organização curricular nos cursos de licenciatura, que poderiam apresentar, como via alternativa à racionalidade técnica, a razão comunicativa.

\section{Teoria da Ação Comunicativa (TAC), currículo e avaliação}

Jürgen Habermas é um expoente da Escola de Frankfurt que, no entanto, apresenta concepções mais otimistas para o projeto de modernidade que seus antecessores. Consegue superar o pessimismo da primeira geração de frankfurtianos, relançando uma Teoria Crítica que busca fundamentos para uma via de racionalidade ainda não empregada e que não descarta a possibilidade de Emancipação via razão, defendendo que os agentes da comunicação deveriam buscar o Entendimento mútuo através da linguagem, rompendo com assimetrias e imposições. 
A TAC empreendida por Habermas (2012a, 2012b) consiste em um posicionamento radical à racionalidade instrumental, uma teoria com propósito prático e explicação abrangente das relações entre os seres humanos, priorizando a compreensão da sociedade via análise das ações envolvidas. Nesse sentido, as ações se caracterizam em Estratégicas ou em Comunicativas dependendo da forma como as interações são mediadas: se objetivam o êxito (Ações Estratégicas) ou o Entendimento (Ações Comunicativas). A racionalidade inerente ao discurso de interação social de uma comunidade de falantes deve ser entendida pela capacidade dos sujeitos em falar e agir, que nas condições da TAC, deve buscar, além do Entendimento, processos de socialização e integração social.

Para Bettine (2017), Jürgen Habermas se amparou nos elementos clássicos das ciências sociais para sua elaboração teórica. Habermas (2012a, 2012b), apoiado em Austin (1993), reconstitui o conceito dos Atos de Fala, a saber: Locucionários, Ilocucionários e Perlocucionários. No Ato de Fala Iocucionário, o falante expressa o estado das coisas, ou seja, diz algo sobre um fato. No Ato Ilocucionário, ao conhecer suas pretensões, o falante expressa vontade de que o outro compreenda o que se diz, sendo mediado pela intenção comunicativa. Ao contrário, no Ato Perlocucionário, o discurso do falante produz efeito sobre o ouvinte, que é persuasivo, perlocutório e que repreende.

Efeitos perlocucionários só podem ser almejados com o auxílio de ações de fala
quando estas são incluídas como meio em ações teológicas orientadas ao êxito. Efeitos
perlocucionários são indícios da integração de ações de fala a contextos de interação
estratégica. Estão entre as consequências pretendidas com as aç̃̃es, ou entre os
resultados de uma ação teológica que o autor empreende com a intenção de provocar
certos efeitos em um ouvinte, com auxílio de sucessos ilocucionários. Por certo, ações
de fala só poderão prestar-se a esse fim não ilocucionário de influenciação de um
ouvinte caso sejam apropriadas à obtenção de fins ilocucionários (HABERMAS,
2012a, p. 507).

Assim, para Lódea (2010), os Atos de Fala sempre devem ser proferidos com intenções de chegar a Ação Comunicativa e deveria ser descartada a hipótese do entendimento via Ação Estratégica. Nesse sentido, podemos derivar uma interpretação e nos lançar a pensar que a forma em que as características dos Atos empregados em discursos podem servir de guia para que o indivíduo (ou a instituição) “[...] não caia ou permaneça no hemisfério da ação estratégica, sabendo resgatar discursivamente suas pretensões de validade da ação comunicativa" (LÓDEA, 2010, p. 68). Assim sendo, parece pertinente questionar o discurso oficial do Conselho Nacional de Educação (CNE) sobre formação de professores, expresso em diretrizes para elaboração de currículos, acerca dos tipos de Atos de Fala que emprega para se fazer inteligível. Isto posto, numa convergência para o entendimento da Ação Comunicativa enquanto possibilidade de coordenação das ações racionais. 
Austin (1993), considerado por Habermas (2012a, 2012b), advoga a força Ilocucionária de uma emissão comunicacional como sendo o poder de um falante para motivar um ouvinte a aceitar um conteúdo expresso em um ato de fala e, com essa força, contrair uma relação racionalmente determinada. Essa afirmação serve de base para pensarmos o conteúdo proposicional de documentos oficiais, relacionados a diretrizes curriculares para formação de professores de Matemática, como discursos oficiais da instituição dada a intermediação e a existência de relações objetivas que se espera estabelecer com os que irão pensar/elaborar/implementar/instituir currículos em/de cursos.

As relações objetivas nos Atos de Fala, de uma instituição como o CNE, introduzem a linguagem como estratégia imperativa de impacto no mundo objetivo, onde o falante exterioriza/expressa formas de induzir o ouvinte (entendendo o leitor também como ouvinte) a atuar de modo que o falante deseja. Essas exteriorizações/expressões passíveis de serem reconhecíveis e acessíveis à análise racional são chamadas de Pretensões de Validade que, ao serem emitidas, podem ter características e funções diferentes dentro da tentativa de entendimento, a saber descritivas (comprometidas com a inteligibilidade), normativas (comprometidas com escolhas de manifestações corretas, com relação às normas e valores falante e ouvinte possam coincidir entre si no que se refere à essência normativa), credíveis (comprometidas com manifestações sinceras, para que o ouvinte possa crer/confiar no falante) e proposicionais verídicas (comprometidas com conteúdo considerado verdadeiro pelos interlocutores). Por conseguinte, a partir dessa diferenciação, determinam a forma como são validadas pelos ouvintes (HABERMAS, 2012a).

Os princípios habermasianos de contraposição à racionalidade instrumental torna possível não só analisar a racionalidade subjacente em discursos encarregados de expressarem Diretrizes Curriculares, mas também a própria concepção de currículo que, por vezes, tem se feito presente nos contextos educacionais. Nesse caminho, a partir das contribuições de Jurgen Habermas e tantos outros pensadores vinculados à Teoria Crítica, se delineia uma concepção sobre a racionalidade, orientadora de organização e desenvolvimento curricular, segundo a qual só é possível atingir o Entendimento - ou Emancipação - em contextos antagônicos à Ação Estratégica. Atrelado a uma concepção, que supere um paradigma instrumental, Pacheco (2001; 2014; 2018) defende a necessidade de perspectivas críticas para o campo curricular.

A teoria crítica do currículo que, segundo Guimarães (2014), vem discutir o currículo como elemento e ambiente ideológico, disputas de poder, resistência e questionamento aos modelos de reprodução social, defende uma visão humanista, humanitária e intersubjetiva sob um discurso marcadamente crítico (PACHECO; SOUZA, 2016). Nesse sentido, todas e todos 
os envolvidos conhecem e reconhecem a racionalidade que subjaz às ações das quais participarão, inclusive com papel autoral.

Canavarro (2003) considera que, a teoria crítica do currículo é resultado de uma ação coletiva, expressa por consciência crítica, considerando o currículo como uma práxis valorativa da atividade Emancipatória. Sendo assim,

[...] inscrita numa tradição marxista, a teoria crítica do currículo é um espaço de contestação, uma outra forma de olhar a realidade e um compromisso político com o que pensamos e fazemos, na medida em que a neutralidade "existe" somente nas explicações técnicas (PACHECO, 2001, p. 50-51).

Ainda em relação à teoria crítica do currículo destaca-se o papel atribuído à escola como ambiente de potencial Emancipação humana e, nesse sentido, o currículo torna-se elemento determinante e condicionante das relações de forças que se estabelecem (APPLE, 2006; FERNANDES, 2019). Isto posto, pois as relações de poder envolvidas no processo de organização e desenvolvimento curricular caracteriza-se como estrutura basilar das pretensões de validade dos discursos que expressam a função social da escola (SILVA, 2017).

Para Pacheco (2007), o currículo é um propósito que, não neutro de informações, corresponde a um conjunto de intenções associadas a comunicação que relaciona significados sociais e historicamente válidos. Sendo assim, um currículo de formação de professores de Matemática resguarda um modo de organização de expressão de discursos acerca do pensamento sobre os assuntos, definições, conceitos e proposições que são importantes para o desenvolvimento e evolução do ser humano, do profissional e do formador de outros seres humanos. O referido propósito, ainda, é marcado pela forma como se compromete com as necessidades desse ser humano e futuro professor para interagir no contexto social e político em que as ações educativas, implicando

[...] ver também o currículo numa dimensão política da educação, ou seja, como um instrumento que reflecte quer as relações sempre existentes entre escola e sociedade, quer os interesses individuais e os de grupo, quer ainda os interesses políticos e ideológicos. [...] o currículo é uma construção permanente de práticas, com um significado marcadamente cultural e social, e um instrumento obrigatório para análise e melhorias das decisões educativas (PACHECO, 2007, p. 19).

Nesse sentido, Freitas (2014) considera que a escola sempre foi um terreno marcado por disputas ideológicas. Nas últimas décadas essas disputas agregaram um elemento polêmico: as avaliações internas e externas às escolas. Para o autor, nos últimos anos, a avaliação, principalmente aquela externa e em larga escala, passou a ocupar um lugar central no interior das instituições escolares, sendo responsável por orientar o currículo escolar.

Na disputa pela escola, os reformadores empresariais da educação ampliaram a função da avaliação externa e deram a ela um papel central na indução da padronização como forma de permitir o fortalecimento do controle não só sobre a cultura escolar, mas 
sobre as outras categorias do processo pedagógico, pelas quais se irradiam os efeitos da avaliação, definindo o dia a dia da escola (FREITAS, 2014, p. 1093).

Ainda para Freitas (2014), avaliar é um tema recorrente em discussões de políticas e programas governamentais para Educação. Nesse cenário, o professor tem que lidar com o discurso do Estado, por meio das avaliações externas, tentando assumir o controle do processo pedagógico das escolas e disputando forças sociais com grupos políticos e econômicos liberalconservadores, com o intuito de controle dos processos de avaliação interno às escolas. Nesse sentido, ainda para o autor, a avaliação educacional tem se tornado mercadoria reduzida “"[...] às avaliações externas que influenciam o quê o professor e a escola assumem como conteúdo e como método" (FREITAS, 2014, p. 1094).

A avaliação externa tem impactado a configuração do currículo escolar (MENEGÃO, 2016) e tem, juntamente com as políticas de reformas curriculares, impactado as práticas de professoras e professores de Matemática (PERALTA, 2019). Práticas essas que, segundo Garcia (2013), especialmente no que se refere a avaliar aprendizagens, foram/são marcadas por uma forte dimensão instrumental vinculadas ao que é externo à escola, quando o esperado é que as práticas de avaliação sirvam a princípios de soberania, combatendo a subordinação e comprometidas com dimensão formativa nos interior das escolas.

Parece ser possível esperar que a avaliação seja

[...] democrática, dialógica e solidária, no sentido de torná-la mais focada na qualidade da formação do aluno e na qualificação dos processos de gestão escolar e do trabalho educativo, ampliando os espaços de participação de todos os sujeitos e instâncias envolvidos e/ou afetados pelo processo avaliativo (GREGO, 2012, p. 78).

Isto posto, advogamos que o discurso de e sobre avaliação, sob forte influência do paradigma de sistemas externos e em larga escala, tem sido mobilizado por força de Atos de Fala Perlocutórios em claro sinal, como adverte Habermas (2012a), de indícios de Ações Estratégicas orientadas pela racionalidade instrumental. No entanto, resistir ao discurso do externo como balizador do processo avaliativo interno requer das professoras e professores de Matemática superação de paradigmas que a(o)s coloquem em papel secundário, restringindoa(o)s a mera(o)s executora(e)s (PERALTA; RODRIGUES, 2017; PERALTA, 2019; RODRIGUES; PERALTA, 2020). 


\section{Análise das Diretrizes Curriculares}

\subsection{Um pouco de historicidade}

A preocupação com a formação de professores para o "secundário" (Anos Finais do Ensino Fundamental e o Ensino Médio), para Gatti (2010), se dá no início do século XX, um período marcado por poucas escolas secundárias, bem como o número de alunos. Para a autora, a partir de 1930, com a formação de bacharéis nas poucas universidades existentes, acrescentouse um ano com disciplinas da área de Educação para a obtenção da licenciatura. Tal modelo ficou conhecido como " $3+1$ ", três anos dedicados aos conhecimentos específicos de Matemática e um ano dedicado aos conhecimentos pedagógicos. Ou seja, nesse modelo de formação docente, os estudantes concluíam o curso de bacharelado e recebiam licença para a carreira específica, e, posteriormente, faziam um curso de complementação didática que lhe conferia o grau de licenciado.

A primeira Lei de Diretrizes e Bases da Educação Nacional (LDB) foi publicada em $1961 \mathrm{sob}^{\circ}$ 4.024/61 (BRASIL, 1961) e, apesar das propostas de enfatizar a natureza pedagógica da licenciatura, registrou redução na duração das disciplinas de cunho pedagógico de 1/4 para 1/8 da carga horária total do curso. Desse modo, houve a tentativa de romper com o modelo 3+1, porém, a formação docente continuou fragmentada (ARAÚJO; VIANA, 2010).

No ano de 1971 foi instituída a LDB, sob o n 5.692/71 (BRASIL, 1971), propondo reflexões amplas e instigando reformas nas instituições de Ensino Superior e no pensamento dos formadores. Ainda para Araújo e Viana (2010), a lei n 5.692/71 também fixou a formação mínima para o exercício do Magistério, introduzindo no cenário educacional brasileiro, as licenciaturas de curta duração, com carga horária variando entre 1200 e 1500 horas, contra 2200 a 2500 horas das licenciaturas plenas.

Almejando alterações nos cursos de formação de professores, a Lei $n^{\circ}$ 5.692/71 (BRASIL, 1971) foi substituída pela mais recente LDB, a Lei 9.394/96 (BRASIL, 1996), que trouxe mudanças às instituições formadoras, com prazo de 10 anos para sua efetiva adequação, e também regulamentou as diretrizes curriculares para todos os cursos de Graduação (bacharelado e licenciatura). Assim, as diretrizes curriculares nacionais têm sua origem na LDB de 1996 e trazem maior flexibilidade curricular para a organização dos cursos de licenciatura em Matemática, abordando normas obrigatórias fixadas pelo Conselho Nacional de Educação (CNE), que orientam as Instituições de Ensino Superior (IES) a estruturarem seus currículos, metas e objetivos a serem alcançados para cada curso, contemplando elementos essenciais de 
cada área.

As Diretrizes Curriculares Nacionais abordam princípios e propostas amplas, não definem conteúdos propriamente, mas dão orientações para a proposição de currículos de formação docente inicial e continuada. Ao enfatizarem a necessidade de um projeto de formação, a partir da articulação entre as IES e o sistema de Ensino Básico, institucionalizam a formação inicial com o objetivo de fomentar nos cursos de licenciatura em Matemática identidade própria, respeitando uma dimensão nacional comum.

Considerando o que foi acima exposto, as seções seguintes deste texto tratam da descrição e análise das Diretrizes Curriculares para Formação Inicial de Professores da Educação Básica, das Diretrizes Curriculares para a Formação de Professores de Matemática, no que se refere à formação para avaliar na formação inicial de professores, perseguindo os pressupostos de Habermas (2012a, 2012b, 2014).

\title{
3.2 Diretrizes Curriculares para Formação Inicial e Continuada de Professores da Educação Básica
}

As Diretrizes Curriculares Nacionais para a Formação Inicial em Nível Superior e para a Formação Continuada em Nível Superior de Profissionais do Magistério para a Educação Básica entrou em vigor pela Resolução N² /2015, tendo por base o Parecer CNE/CP 02/2015, aprovado pelo CNE em junho de 2015.

\begin{abstract}
Art. $1^{\circ}$ Ficam instituídas, por meio da presente Resolução, as Diretrizes Curriculares Nacionais para a Formação Inicial e Continuada em Nível Superior de Profissionais do Magistério para a Educação Básica, definindo princípios, fundamentos, dinâmica formativa e procedimentos a serem observados nas políticas, na gestão e nos programas e cursos de formação, bem como no planejamento, nos processos de avaliação e de regulação das instituições de educação que as ofertam (BRASIL, 2015b, p.02, grifo nosso).
\end{abstract}

Já no primeiro parágrafo nos deparamos com um discurso normativo, próprio de legislações, amparado em Atos de Fala Perlocucionários (Ficam instituídas; definindo princípios [...] a serem observados [...] nos programas e cursos [...]) dirigidos aos endereçados, expressando pretensão de validade, ou seja, pretende que o dito seja válido num sentido amplo e impacte no comportamento do ouvinte. Então, Habermas (1989) defende que, quando se fala algo, pretende-se que aquilo seja válido e, nesse caso da Resolução No 2 de 01/07/201, o ato do locutor, que fala pelo documento legal, enunciando em certas condições e com certas intenções, expressar-se de tal forma que intenção de execução vem associada ao significado dos enunciados. 
Habermas (2012a, 2012b), interpretando a função dos Atos de Fala, demonstra que o mundo social é pautado em processos de produção de linguagem, mediados pela fala, na medida em que os reconstrói e admite que os requisitos nos planos de ação e ajuste, aos ordenamentos vigentes, são condições para se chegar às pretensões de validade e interação de/entre sujeitos. Assim sendo, os Atos de Fala empregados são elementos de mediação entre as intenções de quem fala por meio do documento e aqueles que serão responsáveis por configurar currículos, considerando diretrizes nacionais.

$\S 2^{\circ}$ As instituições de ensino superior devem conceber a formação inicial e continuada dos profissionais do magistério da educação básica na perspectiva do atendimento às políticas públicas de educação, às Diretrizes Curriculares Nacionais, ao padrão de qualidade e ao Sistema Nacional de Avaliação da Educação Superior (Sinaes), manifestando organicidade entre o seu Plano de Desenvolvimento Institucional (PDI), seu Projeto Pedagógico Institucional (PPI) e seu Projeto Pedagógico de Curso (PPC) como expressão de uma política articulada à educação básica, suas políticas e diretrizes (BRASIL, 2015b, p. 03, grifo nosso).

Assim como Habermas (2012a) ensina que o Ato Perlocucionário surge como tentativa de efeito no ouvinte e possui, a priori, finalidade manipuladora, ou mesmo estratégica, do locutor, entendemos que o texto da Resolução N²/2015 mantém um discurso concernente a uma função normativa, regulatória e orientadora de ações. Assim sendo, o que for disposto em seu discurso tem prioridade na organização e desenvolvimento curricular dos cursos de formação.

A característica Perculocionária dos Atos de Fala perpassa por todo o discurso, sendo evidenciada pelo alto teor prescritivo do documento. No entanto, especialmente, em relação a formar para o avaliar, as prescrições são discretas e dispersas. Das vinte e cinco vezes que o vocábulo "avaliação" aparece no texto da Resolução N²/2015, em apenas duas, "avaliação de estudantes" e "avaliação de processos educativos dentro de instituições educacionais", pode-se empreender um esforço e apreender do discurso alguma pretensão relacionada a avaliar aprendizagem. 


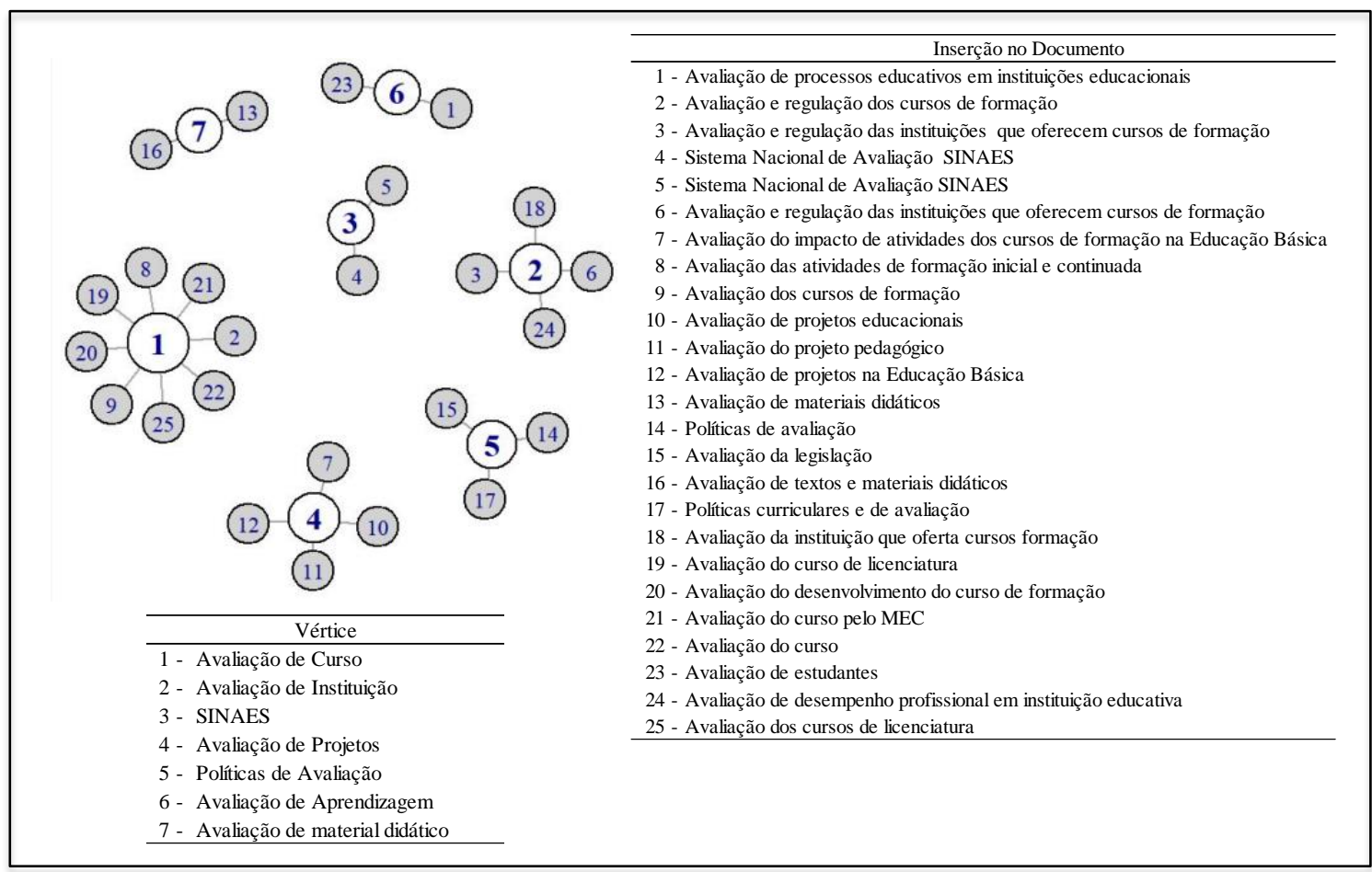

Figura 1 - Rede de relações entre a forma e a frequência que o vocábulo "avaliação" é inserido no texto da Resolução No2/2015

Fonte: As autoras (2020).

A Figura 1, via representação por Grafos ${ }^{2}$, ilustra a relação de como o vocábulo “avaliação" aparece (em cada uma das 25 inserções) no texto da Resolução, a frequência com que ele aparece e as ligações (arestas) com uma das categorias (vértices) que estabelecemos dentro de uma estrutura de rede. Observar quais são as categorias mais influentes dentro da rede, por meio da centralidade que o vértice ocupa, possibilita inferir que "avaliação" relacionada a "avaliação de cursos" é a mais influente, baseando-se no número total de relações (8 arestas) que ele possui com outros vértices da rede, seguido de "avaliação da Instituição" e "avaliação de projetos". Ou seja, o tema avaliação aparece com maior frequência no documento quando atrelado a processos sistemáticos de acompanhamento institucionais.

A formação, como explicitada na Resolução №2/2015, requer uma identidade própria para o licenciado, garantindo a articulação com o contexto educacional, faculdades e centros de Educação em suas dimensões sociais, políticas, culturais, econômicas e tecnológicas, recursos pedagógicos, atividades coletivas e um projeto que assegure o domínio do conteúdo específico da área de atuação (BRASIL, 2015b). Porém, observamos orientações sem muitas especificações, que recomendam formação em conhecimentos específicos em articulação com os aspectos práticos de aplicação e em conhecimentos de cunho pedagógico, mas sem se comprometer a detalhar quais são as necessidades de formação para atuação, em contexto real,

\footnotetext{
${ }^{2}$ Elaborado com o auxílio do Programa R, disponível em https://www.r-project.org/.
} 
diante das demandas educacionais atuais que devem ser contempladas.

\subsection{Diretrizes Curriculares para a formação de professores de Matemática}

As Diretrizes Curriculares para os Cursos de Matemática englobam a licenciatura e o bacharelado, com aprovação pelo Parecer CNE/CES 1.302/2001 (BRASIL, 2002) e homologação pela Resolução CNE/CES 3/2003 (BRASIL, 2003), tem como objetivo orientar a formulação do projeto pedagógico dos cursos. “Art. $1^{\circ}$ As Diretrizes Curriculares para os cursos de bacharelado e licenciatura em Matemática, integrantes do Parecer CNE/CES 1.302/2001, deverão orientar a formulação do projeto pedagógico do referido curso". (BRASIL, 2003, p. 01, destaque nosso).

A exemplo da Resolução No2/2015, os Atos de Fala empregados podem ser caracterizados pela Perlocucionaridade com que se apresentam. Tal como afirma Habermas (2014), nas sociedades a validade da norma se ancora, predominantemente, no resgate discursivo dos argumentos e nas justificações. O texto da referida resolução, locutor do discurso do CNE, evidencia pretensões de validade, segundo as quais, se faz legitimador de regras para formulação de projetos pedagógicos de cursos e a linguagem empregada para fazê-lo assume um papel fundamental. Os Atos de Fala empregados nas diretrizes impactam coordenação de ações e ajustam as dissenções fáticas de tal modo que a organização e desenvolvimento curricular dos cursos de Matemática sejam, discursivamente, orientados.

Como o documento que expressa a Resolução №2/2015 é muito sucinto e se diz integrante do Parecer CNE/CES 1.302/2001, portanto recorremos a este para análise. O primeiro tópico abordado pelo Parecer (BRASIL, 2002) refere-se ao perfil dos formandos. Para os cursos de bacharelado o documento define como objetivo central a qualificação dos estudantes visando a pesquisa e o Ensino Superior, além de uma sólida base de conteúdos matemáticos específicos e suas áreas de aplicação. Para a licenciatura, define que o licenciado em Matemática deve ter

- Visão de seu papel social de educador e capacidade de se inserir em diversas realidades com sensibilidade para interpretar as ações dos educandos.

- Visão da contribuição que a aprendizagem da Matemática pode oferecer à formação dos indivíduos para o exercício de sua cidadania.

- Visão de que o conhecimento matemático pode e deve ser acessível a todos, e consciência de seu papel na superação dos preconceitos, traduzidos pela angústia, inércia ou rejeição, que muitas vezes ainda estão presentes no ensino-aprendizagem da disciplina (BRASIL, 2002, p.03, destaque nosso).

Dentre as características desejáveis a um licenciado em Matemática listadas no documento, a citada sensibilidade para interpretar ações dos educandos pode ser entendida 
como capacidade para avaliar? Mesmo em caso afirmativo, a necessidade de interpretação já denota falta de reconhecimento do saber avaliar como uma necessidade formativa de futuros professores de Matemática. O conhecimento específico de Matemática, ao contrário, se faz presente nominalmente com muita recorrência.

Um (re)formulador de estrutura curricular pode interpretar que, ao listar no projeto político pedagógico as competências e habilidades específicas, requeridas de serem objetos de formação, há a possibilidade de incluir o saber avaliar aprendizagens, ou, ainda, que seja possível incluir o formar para avaliar como conteúdo curricular da formação inicial. E também que as formas de avaliação a serem vivenciadas pelos licenciandos possam servir de modelos a serem implementados em suas futuras práticas avaliativas. Enfim, mais uma vez, as possibilidades ficam passíveis de interpretação.

\begin{abstract}
No que se refere às competências e habilidades próprias do educador matemático, o licenciado em Matemática deverá ter as capacidades de a) elaborar propostas de ensino-aprendizagem de Matemática para a educação básica; b) analisar, selecionar e produzir materiais didáticos; c) analisar criticamente propostas curriculares de Matemática para a educação básica; d) desenvolver estratégias de ensino que favoreçam a criatividade, a autonomia e a flexibilidade do pensamento matemático dos educandos, buscando trabalhar com mais ênfase nos conceitos do que nas técnicas, fórmulas e algoritmos; e) perceber a prática docente de Matemática como um processo dinâmico, carregado de incertezas e conflitos, um espaço de criação e reflexão, onde novos conhecimentos são gerados e modificados continuamente; f) contribuir para a realização de projetos coletivos dentro da escola básica (BRASIL, 2002, p.03, destaque nosso)
\end{abstract}

Habermas (2014) insiste na substituição da Ação Estratégica orientada por fins próprios que, baseada no indivíduo por meio de sua consciência, chega à norma, pela Ação Comunicativa, baseada numa pluralidade de indivíduos que orientarão a ação por procedimentos discursivos, chegam à norma. E ainda, retomando as pretensões de validade, se a problemática de interpretação, mencionada no parágrafo anterior, estivesse na pretensão de inteligibilidade ter-se-ia que recorrer a aspectos ilocucionários no discurso.

O Parecer (BRASIL, 2002) e as Diretrizes (BRASIL, 2003) parecem estar comprometidos com a predominância de uma arena permeada por relações que zelam por instruir/informar/orientar/regular, mas sem garantias de Entendimento.

Especificamente, em relação ao formar para avaliar, o silenciamento prevalece. No texto da Resolução CNE/CES 3/2003 o vocábulo “avaliação" não aparece e no texto do Parecer CNE/CES 1.302/2001 pode ser encontrado uma única vez, a saber: "O projeto pedagógico de formação profissional a ser formulado pelo curso de Matemática deverá explicitar: a) o perfil dos formandos [...] g) as formas de avaliação" (BRASIL, 2002, p. 01). Em contrapartida, conhecimentos específicos de Matemática são citados nominalmente, e de forma recorrente. 
A forma e a frequência, com que se apresenta, ou não, no documento o vocábulo "avaliação", faz dessas prescrições um dispositivo facilitador de esquiva ao compromisso do Estado de institucionalizar a necessidade sistemática de formação para avaliar aprendizagens. Esse comportamento do Estado parece não proporcional aos esforços depreendidos por ele para implantar políticas de avaliação que têm impactado, desde a década de 1990, nas demandas cotidianas dos professores no exercício da profissão (LOPES JR; PERALTA, 2015).

\subsection{Considerações}

Da forma como se apresentam, os textos que descrevem as Diretrizes (BRASIL, 2003, 2015b) podem oferecer precedentes à formação de professor de Matemática que privilegie aspectos técnicos e instrumentais da dimensão específica do conhecimento matemático, sem o devido compromisso com a dimensão pedagógica. Como consequência, a prática avaliativa pode se privar de fundamentos em racionalidade alternativa à instrumental, a saber, a racionalidade comunicativa.

Para Dourado (2015), com a proposição das Diretrizes Curriculares Nacionais para a Formação Inicial e Continuada dos Profissionais do Magistério para a Educação Básica, o CNE buscou abordar maior organicidade nos formatos de instrumentos normativos da formação inicial e continuada. Junqueira e Manrique (2015) acreditam que esses formatos podem ter sido compreendidos pelas entidades formadoras, porém há permanências de heranças do tradicionalismo que se mantém na formação de professores de Matemática.

Habermas (2014) nos alerta que as relações de poder, controle e manipulação, que são exercidas por meio da influência de um discurso dominado por Atos Perlocucionários, evidências de racionalidade instrumental, tentam ocultar o máximo possível suas pretensões estratégicas. No caso dos textos dos documentos curriculares analisados, apesar de nos remeterem a expressões como "analisar criticamente", "espaços de criação e reflexão", "projetos coletivos", "construir e aplicar", "emancipação", "projeto social, político e ético", o emprego de Atos de Fala Perlocucionários na construção do discurso expresso, efetivamente, compromete a construção de Consensos e Entendimentos.

Junqueira e Manrique (2015, p. 628) apontam que a adoção de políticas educacionais buscam, “[...] ao contrário de inovações nos cursos de Licenciatura, prioritariamente, o atendimento de organismos internacionais que regulam o sistema capitalista", destacando que foram encontrados nos documentos oficiais de formação docente, analisados por elas, aspectos que denotam dicotomia entre teoria e prática, supervalorização do conhecimento específico em 
detrimento do conhecimento pedagógico, entre outros - que parecem enraizados, e que teimam em permanecer na constituição e identidade do professor de Matemática. Ainda para as mesmas autoras,

[...] verifica-se também que os conteúdos, da forma como são apresentados nos cursos de Licenciatura em Matemática, não sugerem a construção de uma visão global de maneira significativa para o aluno, estão fragmentados, desvinculados de significados. Nesse sentido o documento é contraditório (JUNQUEIRA; MANRIQUE, 2015, p. $633)$.

Desta forma, há a possibilidade da racionalidade presente nos documentos investigados (BRASIL, 2002b; 2003; 2015a; 2015b) remeter ao que Habermas (2012a, 2012b, 2014), esclarece como Instrumental, pois os documentos são diretrizes para formulações de cursos que podem servir a controles, exigências administrativas e funcionalidades burocráticas. Assim, apesar do modelo " $3+1$ ”, oficialmente, não existir mais, conforme Medeiros (2005), a formação docente ainda aparece amparada na Razão Técnica.

Se as Diretrizes (BRASIL, 2003; 2015b) definem princípios, métodos e propostas mais amplas na formação de professores de Matemática do magistério para Educação Básica, notase a importância dos documentos como elemento orientador na organização curricular dos cursos de licenciatura, na esfera do avaliar e na constituição do formar para a docência da Educação Básica. As Diretrizes (BRASIL, 2003; 2015b), como documentos normativos e elemento de política educacional, orientam projetos pedagógicos de cursos de licenciatura, influenciando a constituição do perfil docente e o controle das ações de Instituições de Ensino Superior, ao impor um tipo de racionalidade nos discursos do documento. Nesse sentido, corroboram o que Muhl (2007) alerta a respeito da

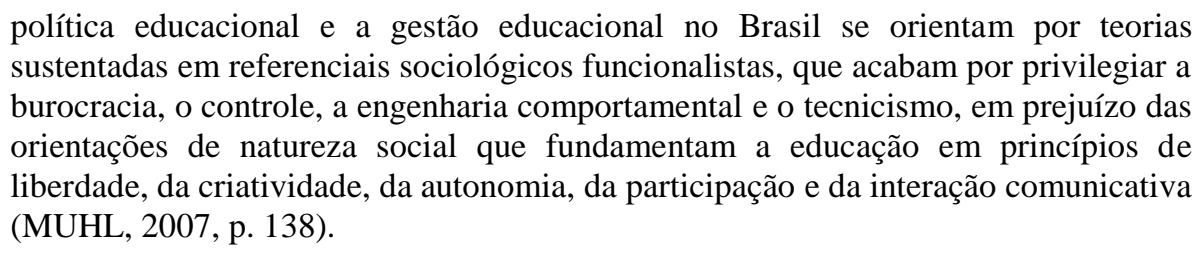

A Matemática vem, há muito tempo, sendo relacionada à excelência do racionalismo científico e, nem sempre, demandando críticas e reflexões sociais. Nesse cenário, a avaliação fica restrita à aplicação de provas e atribuição de notas, sem espaços para debates e Consensos argumentativos com vistas ao Entendimento. Assim sendo, ao "invés de um espaço público de aprendizagem da convivência humana, torna-se, predominantemente, um lugar de aquisição de habilidades e de informações técnicas necessárias para a inserção do indivíduo no sistema do poder e do dinheiro" (MUHL, 2011, p. 1040).

Com efeito antídoto à racionalidade técnica, a TAC proposta por Habermas (2012a, 
2012b) tem como papel central o resgate discursivo dos atores capazes de falar e agir com vistas ao Entendimento em ambientes livres de assimetrias e coerção. A racionalidade comunicativa, indica formas diversas de argumentação, bem como diversas formas de dar prosseguimento ao agir por meio de recursos reflexivos, gerando um comum acordo social advindo de discursos racionalmente motivados. Desta forma, avaliar na perspectiva habermasiana é:

\footnotetext{
Primeiramente possibilitar aos alunos falarem, de modo livre de coerções, podendo fazer uso de todo tipo de expressão, explicação, recomendação e juízo para problematizar as pretensões de validade do constructo alvo de ensino/avaliação. Em seguida, mas não menos importante, é garantir inteligibilidade; verdade nas proposições; normas e regras justas e veracidade dos sujeitos interlocutores (PERALTA, 2017, p. 151).
}

Advogando essa mesma perspectiva para a formação inicial de professores de Matemática, concebe-se uma gama de conhecimentos específico e pedagógico, numa perspectiva crítica de currículo, construindo um encadeamento didático com coerência, sendo capaz de desenvolver nos futuros docentes habilidades, atitudes, valores para orientar sua prática e identidade profissional, de modo a constituir sujeitos conscientes, críticos e responsáveis pela formação de outros. Para tanto, não se faz possível uma hierarquização desses conhecimentos. Assim sendo,

\begin{abstract}
A formação da capacidade discursiva, argumentativa, do professor não a dispensa de uma sólida formação científica. Ao contrário, a condição do desenvolvimento da capacidade argumentativa vincula-se ao domínio científico e técnico dos saberes que lhe compete trabalhar em sala de aula. É impossível o professor desenvolver uma convincente argumentação sem o domínio consistente de conteúdos e de métodos científicos. O que pode impedir um agir comunicativo em sala de aula não é o excesso do saber, mas a falta dele. Aliás, o próprio Habermas demonstrou que um dos fatores impeditivos da comunicação é a falta de domínio de uma determinada linguagem (MUHL, 1999, p. 260).
\end{abstract}

\title{
4 Se for possível uma conclusão, conclui-se...
}

A insuficiência de prescrições/recomendações/orientações/menções explícitas a um formar para avaliar nas Diretrizes pode representar esquivas em expor posicionamento político, falta de reconhecimento em relação ao saber avaliar como necessidade formativa e/ou preocupação em garantir autonomia e liberdade das IES na proposição dos currículos de seus cursos.

Não se trata de cobrar que as Diretrizes recomendem, universalmente, aquilo que compete localmente, mas questionar se, ao se eximir de mencionar, nominalmente, o formar para avaliar como objetivo, conteúdo e/ou compromisso necessário das licenciaturas com a formação dos futuros professores, direta ou indiretamente, isenta os cursos de reforçarem essa necessidade em seus currículos. Prever nas Diretrizes a necessidade de formação para avaliar, 
certamente, não garante que os currículos (re)formulados, a partir delas, contemplem esse formar, mas ao deixar de prescrever/recomendar/orientar/mencionar, as instâncias governamentais podem se desobrigar da responsabilidade de formar o professor para uma das atividades mais demandadas em função das políticas educacionais atuais impostas por essas mesmas instâncias.

Os currículos de licenciatura em Matemática são espaços nos quais interações sociais acontecem e são coordenadas, via mediação da linguagem, por Pretensões de Validade expressas em Atos de Fala. O professor ter o domínio sobre certo conteúdo, avaliar o aluno e objetivar Entendimento e Emancipação das amarras educacionais tradicionalistas e tecnicistas, no sentido de Habermas (2014), não conduz à neutralização do poder na interação, mas em formas de liberdade contratual, constituindo-se em novas relações interativas e comunicativas racionalmente orientadas. A racionalidade empregada é determinante nesse processo.

\section{Agradecimento}

À CAPES (Coordenação de Aperfeiçoamento de Pessoal de Nível Superior) pelo apoio financeiro ao desenvolvimento da pesquisa

\section{Referências}

APPLE, M. W. Ideologia e Currículo. 3. ed. Porto Alegre: Artmed Editora, 2006.

ARAÚJO, R. S; VIANNA, D. M. A história da legislação dos cursos de licenciatura em Física no Brasil: do colonial presencial ao digital a distância. Revista Brasileira de Ensino de Física, São Paulo, v. 32, n. 4, 01-12, 2010.

AUSTIN, J. L. Sentido e Percepção. São Paulo: Martins Fontes, 1993.

BETTINE, M. Um olhar sobre a construção do conceito de ação comunicativa na "Teoria da Ação Comunicativa”. Sociologias, Porto Alegre, v. 19, n. 44, p. 334-359, jan. 2017. Disponível em: http://www.scielo.br/scielo.php?script=sci_arttext\&pid=S151745222017000100334\&lng=en\&nrm=iso. Acesso em: 03 jun. 2020.

BRASIL. Lei ${ }^{\circ}$ 4.024, de 20 de dezembro de 1961. Fixa as Diretrizes e Bases da Educação Nacional. Brasília, 1961. Disponível em: http://www2.camara.leg.br/legin/fed/lei/1960-1969/lei-402420-dezembro-1961-353722-publicacaooriginal-1-pl.html. Acesso em: 25 jan. 2018.

BRASIL. Lei $\mathrm{n}^{\mathbf{0}}$ 5.692, de 11 de agosto de 1971. Fixa diretrizes e bases para o ensino de $1^{\circ}$ e $2^{\circ}$ graus, e dá outras providências. Brasília, 1971. Disponível em: http://www2.camara.leg.br/legin/fed/lei/19701979/lei-5692-11-agosto-1971-357752-publicacaooriginal-1-pl.html. Acesso em: 25 jan. 2018.

BRASIL. Lei $\mathbf{n}^{\mathbf{0}}$ 9.394, de 20 de dezembro de 1996. Estabelece as diretrizes e bases da educação nacional. Brasília, 1996. Disponível em:

http://portal.mec.gov.br/seesp/arquivos/pdf/lei9394_ldbn1.pdf. Acesso em: 25 jan. 2018. 
BRASIL. Conselho Nacional de Educação. Parecer CNE/CES 1.302/2001. Diretrizes curriculares nacionais para os cursos de matemática, bacharelado e licenciatura. Brasília, 2002. Disponível em: http://portal.mec.gov.br/cne/arquivos/pdf/CES13022.pdf. Acesso em: 25 jan. 2018.

BRASIL. Conselho Nacional de Educação. Resolução CNE/CES, de 18 de fevereiro de 2003. Estabelece as Diretrizes Curriculares para os cursos de Matemática. Brasília, 2003. Disponível em: http://portal.mec.gov.br/cne/arquivos/pdf/ces032003.pdf. Acesso em: 25 jan. 2018.

BRASIL. Conselho Nacional de Educação. Parecer CNE/CP no 2/2015. Diretrizes Curriculares Nacionais para a Formação Inicial e Continuada dos Professores do Magistério da Educação Básica. Brasília. 2015a.Disponível em:

http://portal.mec.gov.br/index.php?option=com_docman\&view=download\&alias=17625-parecer-cnecp-2-2015-aprovado-9-junho-2015\&category_slug=junho-2015-pdf\&Itemid=30192. Acesso em: 05 jun. 2020.

BRASIL. Conselho Nacional de Educação. Resolução CNE/CP 2/2015. Diretrizes Curriculares Nacionais para a formação inicial em nível superior (cursos de licenciatura, cursos de formação pedagógica para graduados e cursos de segunda licenciatura) e para a formação continuada. Brasília, 2015b. Disponível em:

http://portal.mec.gov.br/index.php?option=com_docman\&view=download\&alias=17719-res-cne-cp002-03072015\&category_slug=julho-2015-pdf\&Itemid=30192. Acesso em: 05 jun. 2020.

CANAVARRO, A. P. Práticas de ensino da matemática: duas professoras, dois currículos. 2003. 548 f. Tese (Doutorado em Educação) - Universidade de Lisboa, Lisboa, 2003.

CELLARD, A. A análise documental. In: POUPART, J. A pesquisa qualitativa: enfoques epistemológicos e metodológicos. Petrópolis: Vozes, 2008. p. 295-316.

DOURADO, L. F. Diretrizes Curriculares Nacionais para a formação inicial e continuada dos profissionais do magistério da Educação Básica. Educação e Sociedade, Campinas, v. 36, n. 131, p. 299- 324, 2015.

FERNANDES, D. Avaliações externas e aprendizagens dos alunos: uma reflexão crítica. Linhas Críticas, Cidade, v. 25, n. 10 p. 74-90, jul. 2019. Disponível em:

https://periodicos.unb.br/index.php/linhascriticas/article/view/24579. Acesso em: 05 jun. 2020.

FREITAS, L. C. Os reformadores empresariais da educação e a disputa pelo controle do processo pedagógico na escola. Educação \& Sociedade, Campinas, v. 35, n. 129, p. 1085-1114, 2014.

GARCIA, R. P. M. Avaliação da aprendizagem na educação a distância na perspectiva comunicacional. Cruz das Almas: Editora UFRB, 2013.

GATTI, B. A. Formação de professores no Brasil: características e problemas. Educação e Sociologia, Campinas, v. 31, n. 113, p. 1355-1379, out./dez. 2010.

GREGO, S. M. D. Reformas Educacionais e Avaliação: mecanismos de regulação na escola. Estudos em Avaliação Educacional, São Paulo, v. 23, n. 53, p. 60-81, 2012.

GUIMARÃES, Y. A. F. Identidade Curricular na Formação Inicial de Professores de Física. 2014. 511 f. Tese (Doutorado em Ensino de Ciências) - Universidade de São Paulo, São Paulo, 2014.

HABERMAS, J. Mudança estrutural da esfera pública. Tradução de Denilson Luís Werle. São Paulo: Editora Unesp, 2014.

HABERMAS, J. Notas programáticas para a fundamentação de uma ética do discurso. In: 
HABERMAS, J. (org). Consciência Moral e Agir Comunicativo. Tradução de Guido Antônio de Almeida. Rio de Janeiro: Tempo brasileiro, 1989. p.61-141.

HABERMAS, J. Teoria do agir comunicativo I: racionalidade da ação e racionalização social. Tradução de Paulo Astor Soethe. São Paulo: Uwfmartinsfontes, 2012a.

HABERMAS, J. Teoria do agir comunicativo II: sobre a crítica da razão funcionalista. Tradução de Flávio Beno Siebeneichler. São Paulo: Uwfmartinsfontes, 2012b.

JUNQUEIRA, S. M. S; MANRIQUE, A. L. Reformas curriculares em cursos de licenciatura em matemática: Intensões necessárias e suficientes. Ciência e Educação, Bauru, v. 21, n. 23, p. 623-635, 2015.

LÓDEA, A. L. Entendimento e linguagem: uma compreensão da teoria da ação comunicativa de Jürgen Habermas. Guairacá, Guarapuava, v. 26, n. 26, p. 55-79, 2010.

LOPES JUNIOR, J.; PERALTA, D. A. Formação de professores e análise do comportamento: caracterização de necessidades formativas para a docência em matemática na educação básica. Temas em Psicologia (Ribeirão Preto), v. 23, p. 69-81, 2015.

MEDEIROS, A. M. S. Formação de professores sob a perspectiva da teoria crítica e das políticas educacionais. Educação e Linguagem, São Paulo, v. 8, n. 11, p. 195-210, 2005.

MENEGÃO, R. C. S. G. Os impactos da avaliação em larga escala nos currículos escolares. Práxis Educativa, Ponta Grossa, v. 11, n. 3, p. 641-656, 2016.

MULH, E. H. Habermas e a educação: racionalidade comunicativa, diagnóstico crítico e emancipação. Educação e Sociedade, Campinas, v. 32, n. 17, p. 1035-1050, 2011.

MULH, E. H. Racionalidade comunicativa e educação emancipadora. 1999. $287 \mathrm{f}$. Tese (Doutorado em Educação) - Universidade Estadual de Campinas, Campinas, 1999.

MULH, E. H. Racionalidade instrumental e ação comunicativa: Perspectiva democrática e cidadã na gestão educacional. Revista Espaço Pedagógico, Passo Fundo, v. 14, n. 2, p. 137-150, 2007.

PACHECO, J. A; SOUZA. J. O (pós) crítico na desconstrução curricular. Tempos e Espaços da Educação, São Cristóvão, v. 18, p. 65-74, 2016.

PACHECO, J. A. Currículo: teoria e práxis. 3. ed. Porto: Porto Editora, 2007.

PACHECO, J. A. Teoria Curricular Crítica: os dilemas (e contribuições) dos educadores críticos. Revista Portuguesa de Educação, Braga, v. 14, n.1, p. 49-71, 2001.

PACHECO, J. A. Educação, formação e conhecimento. Porto: Porto Editora, 2014.

PACHECO, J. A. Para uma teoria curricular de mercado. In: PACHECO, J. A.; ROLDÃO, M. C.; ESTRELA, M. T. (org.). Estudos de currículo. Porto: Porto Editora, 2018. p. 57-88.

PERALTA, D; A. RODRIGUES, A. F. B. Avaliação como Ação Educativa na Perspectiva do Agir Comunicativo de Jürgen Habermas. Educação Matemática em Revista, Brasília, DF, v. 22, n. 56, p. 143-161, 2017.

PERALTA, D. A. Formação continuada de professores de matemática em contexto de reforma curricular: contribuições da teoria da ação comunicativa. 2012. n. 208 f. Tese (Doutorado em Educação para Ciências) - Universidade Estadual Paulista, Bauru, 2012. 
PERALTA, D. A. Formação de professores em contexto de reforma curricular: Uma proposta habermasiana em Educação Matemática. REVEMAT, Florianópolis, v. 12, n. 1, p. 65-77, 2017.

PERALTA, D. A. Habermas e as professoras e professores de matemática: vislumbrando oásis. 01. ed. Curitiba: Appris, 2019. v. 01. 251p.

POSTINGUE, T. P.; PERALTA. D. A. Avaliação da Aprendizagem como elemento curricular nas Licenciaturas em matemática das Universidades Estaduais Paulistas: Uma carência declarada. Perspectivas da Educação Matemática, Campo Grande, MS, v. 11, n. 27, p. 978-1001, 2018.

RODRIGUES, A. F. B.; PERALTA, D. A. Currículo, matemática e ação educativa: a Escola Maria Peregrina na perspectiva do agir comunicativo. REVEMAT, Florianópolis, v. 15, p. 1-22, maio 2020. ISSN 1981-1322. Disponível em: <https://periodicos.ufsc.br/index.php/revemat/article/view/19811322.2020.e67840>. Acesso em: 03 jun. 2020.

SILVA, T. T. Documentos de identidade: uma introdução às teorias do currículo. 3. ed. Belo Horizonte: Autêntica, 2017. 